\title{
Kemampuan Tempurung Kelapa sebagai Panel Akustik Refuser (Resonator-Difuser) dalam Menyerap dan Mengisolasi Bunyi
}

\author{
Susilo Indrawati*, Suyatno, dan Lila Yuwana \\ Departemen Fisika, Fakultas Sains, Institut Teknologi Sepuluh Nopember (ITS) \\ Kampus ITS Sukolilo, Surabaya 60111
}

\begin{abstract}
Intisari
Permasalahan gema pada ruang besar (auditorium) dapat diatasi dengan pemberian absorber. Namun pemberian absorber permasalahan distribusi bunyi yang tidak merata akan kembali muncul. Oleh karena itu pada penelitian ini dilakukan penggabungan dua fungsi material yaitu sebagai resonator dan diffuser yang kemudian disingkat refuser. Bahan yang digunakan adalah tempurung (batok) kelapa. Batok kelapa dipotong persegiempat dengan ukuran $3 \mathrm{~cm} \times 3 \mathrm{~cm}$, dengan pemberian lubang ditengahnya sekitar $1 \mathrm{~mm}$ dan disusun menyerupai mosaic. Mosaic dipadukan dengan rockwool menjadi refuser (resonator-difuser). Pembuatan refuser selain sebagai resonator juga diharap mampu mendiffuskan bunyi (diffuser). Pengujian yang dilakukan terdiri dari dua macam pengukuran yaitu menentukan nilai koefisien absorbsi $(\alpha)$ dan noise reduction (NR). Metode pengujian menggunakan metode tabung impedansi. Pengujian ini dilakukan untuk mengetahui kemampuan refuser dalam mengabsorbsi dan mengisolasi bunyi. Hasil dari pengujian didapatkan penambahan mosaic (batok kelapa) mampu meningkatkan nilai $\alpha$ pada frekuensi $250 \mathrm{~Hz}$ menjadi dua kali lipat menjadi 0,64. Sehingga dapat dikatakan bahwa refuser tersebut mampu bertindak sebagai resonator. Sedangkan nilai NR menunjukkan, penambahan mosaic meningkatkan nilai NR pada frekuensi di atas $1000 \mathrm{~Hz}(30-40 \mathrm{~dB})$. Sehingga selain mampu digunakan sebagai absorber pada frekuensi rendah $(250 \mathrm{~Hz})$ juga mampu mereduksi bunyi pada frekuensi tinggi $(\geq 1000 \mathrm{~Hz})$.
\end{abstract}

\begin{abstract}
Echoes in auditorium could be improved by adding absorbent materials. The consequence of this is an emerge of various sound distribution. Therefore, this article performs the combination of two functions of a material, i.e as resonator and diffuser (known as refuser"). Coconut shells are cut into rectangles with a size of $3 \mathrm{~cm} \times$ $3 \mathrm{~cm}$, and given holes in the middle of about $1 \mathrm{~mm}$ and arranged into mosaic. Then, mosaic is combined with rockwool to be a refuser. The tests involve two types of measurements, i.e determining the value of the absorption coefficient $(\alpha)$ and noise reduction (NR). These test method uses the impedance tube method to determine the ability of the refuser to absorb and isolate the sound. The results shows that the addition of the mosaic (coconut shells) is able to double the value of to 0.64 at a frequency of $250 \mathrm{~Hz}$. In other words, the refuser could behave as a resonator. Furthermore, the refuser is able to increases the NR value at frequencies above $1000 \mathrm{~Hz}(30-40$ $\mathrm{dB})$ and able to be used as absorber sound at low frequency $(250 \mathrm{~Hz})$ and in higher frequencies $(\geq 1000 \mathrm{~Hz})$.
\end{abstract}

Keywords: adsorption coefficients; echo; noise reduction; refuser.

*Corresponding author: susilo@physics.its.ac.id

http://dx.doi.org/10.12962/j24604682.v15i2.5244

2460-4682 @DDepartemen Fisika, FSains-ITS

\section{PENDAHULUAN}

Dalam auditorium tertutup misalnya concert hall sering kali penonton mengeluh mengenai kenyamanan pendengaran. Penonton yang berada di tempat duduk baris- baris bagian depan akan mendengar suara-suara yang sangat keras. Hal ini terjadi bila hanya beberapa loudspeaker dipasang di depan dengan pengaturan tingkat suara yang terlalu keras. Sebaliknya penonton yang berada di belakang kemungkinan besar tidak dapat menerima suara dengan baik dan jelas. Salah satu per- syaratan kondisi mendengar yang baik dalam suatu auditorium adalah adanya distribusi bunyi yang merata.

Distribusi bunyi dapat merata apabila diberikan material akustik berupa reflektor, namun pemberian reflektor pada ruang yang besar akan mengalami permasalahan gema [1]. Gema dapat diatasi dengan pemberian material absorber, namun dengan pemberian absorber permasalahan pertama yaitu distribusi bunyi yang merata akan muncul lagi. Oleh karena itu diperlukan material khusus yaitu diffuser. Difuser merupakan panel akustik yang mampu mengacak bunyi sehingga 


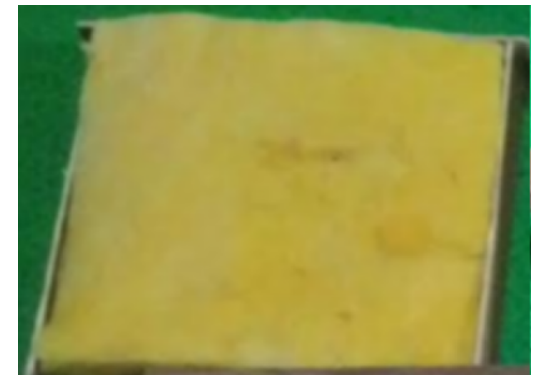

(a) $\mathrm{R}$

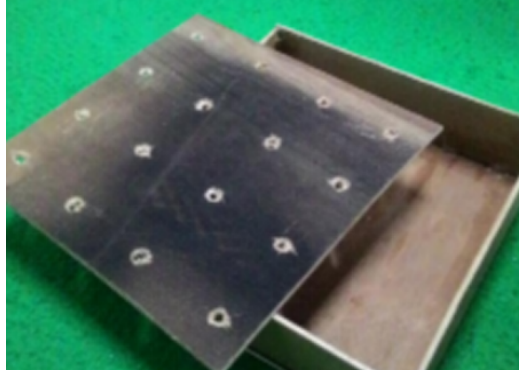

(b) RP

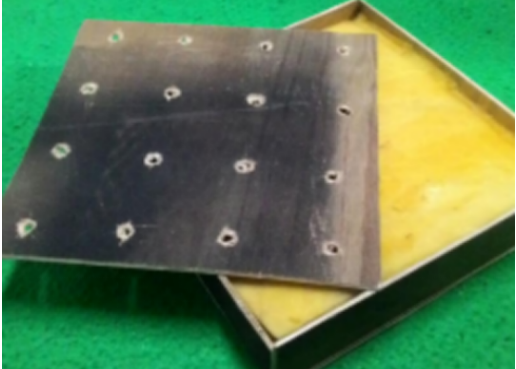

(c) RPR

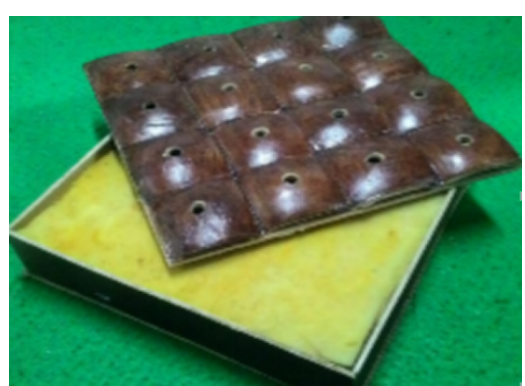

(d) RPM

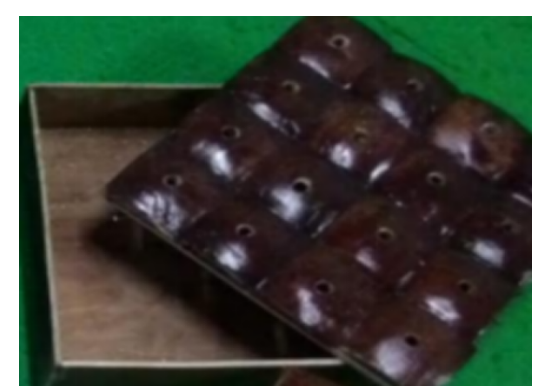

(e) RPMR

Gambar 1: Bahan uji yang diujikan nilai koefisien absorbsi.

ruang tidak menjadi gema. Disamping mampu mengacak bunyi difuser tidak mengurangi energi sehingga permasalahan distribusi bunyi yang tidak merata bisa diatasi [2]. Pembuatan panel diffuser terbuat dari limbah tempurung kelapa pernah dilakukan. Namun diffuser yang dibuat hanya sebatas dari segi estetika [3].

Dalam penelitian sebelumnya [4] tentang CSR (Coconut shell resonator) dari limbah tempurung kelapa muda, diperoleh kesimpulan bahwa bahan tempurung kelapa memiliki kemampuan yang baik dalam menghamburkan bunyi pada frekuensi $1000-5000 \mathrm{~Hz}$ baik disusun secara convex maupun secara concave. Ketika diberi perforasi pada tempurung kelapa juga mengalami perubahan yang drastis mulai frekuensi $1000 \mathrm{~Hz}$. Kemampuan yang unik pada frekuensi tersebut cocok untuk ruang percakapan (speech room). Kelemahan dari penelitian tersebut, bentuk variasi yang digunakan tingkat homogenitasnya yang kurang.

Penelitian ini adalah kelanjutan dari penelitian sebelumnya, dengan menggunakan batok kelapa sebagai bahan utamanya. Menghindari keseragaman bentuk yang tidak homogen akan dilakukan pembuatan resonator-diffuser (refuser) yang memiliki bentuk seperti mozaik. Dalam pengujian refuser, selain dilakukan kemampuannya dalam mengabsorbsi bunyi juga dilakukan pengujian terhadap kemampuannya dalam mengisolasi bunyi.

\section{METODOLOGI}

Penelitian yang dilakukan ini terdiri dari dua macam pengukuran, yaitu pengukuran koefisien absorbsi $(\alpha)$ dan pengukuran Noise Reduction (NR).

\section{Pembuatan panel akustik refuser}

Pembuatan panel refuser ini adalah mengadopsi dari bentuk resonator yang terbuat dari rockwool yang dilapisi oleh triplek yang telah dilubangi. Beberapa material yang dipilih dalam penelitian ini adalah rockwool. Variasi yang dibuat untuk pengukuran nilai koefisien absorbsi ada lima (5) macam sampel:

1. Sampel $\mathrm{R}$ adalah rockwool setebal $4 \mathrm{~cm}$ dengan ukuran $16 \mathrm{~cm} \times 16 \mathrm{~cm}$,

2. Sampel RP adalah resonator yang terbuat dari kotak triplek berlubang kosong, ukuran $16 \mathrm{~cm} \times 16 \mathrm{~cm}$ dengan kedalaman $4 \mathrm{~cm}$,

3. Sampel RPR adalah resonator seperti pada resonator kedua (RP) namun ditambah dengan rockwool,

4. Sampel RPM adalah resonator seperti pada resonator kedua (RP) ditambah susunan mozaik (batok ukuran 4 $\mathrm{cm} \times 4 \mathrm{~cm}$ yang disusun seperti mozaik,

5. Sampel RPMR adalah resonator seperti pada resonator ketiga (RPR) namun ditambah susunan mozaik.

Bentuk detail masing-masing sampel ditunjukkan dalam Gambar 1.

Selain pengukuran koefisien absorbsi juga dilakukan pengukuran berhubungan dengan kemampuan dalam mentransmisikan bunyi. Parameter pengukuran ini salah satunya adalah NR (Noise Reduction). Dalam pengukuran nilai NR digunakan penambahan material gipsum. Gipsum merupakan material yang sering digunakan sebagai partisi dan memiliki nilai TL yang cukup tinggi. Sampel yang digunakan variasi 


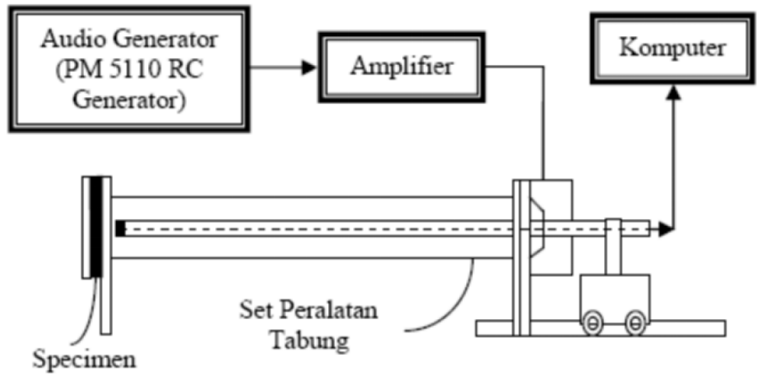

Gambar 2: Susunan peralatan untuk menguji bahan absorpsi.

dalam penelitian ini ada 5 macam yang merupakan variasi dari bahan yang diajukan dalam pengujian koefisien absorbsi. Adapun bahan yang digunakan adalah:

1. Gipsum 1 lapis (G1),

2. Gipsum 1 lapis + RP (G1RP),

3. Gipsum 1 lapis + RPR (G1RPR),

4. Gipsum 1 lapis + RPM (G1RPM),

5. Gipsum 1 lapis + RPMR (G1RPMR).

\section{Pengukuran koefisien absorbsi $(\alpha)$}

Pengukuran absorpsi sampel menggunakan metode "tabung impedansi". Metode tabung impedansi merupakan salah satu cara untuk mengukur absorpsi bahan pada gelombang bunyi. Penggunaan metode ini berdasarkan pada dua standart, yaitu ISO 10534-2:1998 and American Standart for Testing Materials (ASTM) E1050-98, prinsip dasar metode tabung impedansi adalah refleksi, absorpsi dan transmisi gelombang bunyi oleh permukaan bahan pada suatu ruang tertutup, dimana bahan tersebut digunakan untuk melapisi permukaan dinding ruang tertutup. Rangkaian peralatan seperti pada Gambar 2.

Besarnya koefisien absorpsi dihitung dengan menggunakan persamaan:

$$
\alpha_{n}=1-\left(\frac{\log ^{-1}\left(\frac{\Delta S P L}{20}-1\right)}{\log ^{-1}\left(\frac{\Delta S P L}{20}+1\right)}\right)^{2}
$$

dengan $\alpha_{n}$ adalah koefisien absorpsi normal bahan, $\triangle S P L$ aalah selisih nilai SPL maksimum dengan SPL minimum [5].

\section{Pengukuran nilai Noise Reduction (NR)}

Pengukuran NR ini untuk mengetahui kemampuan material dalam mengisolasi bunyi. Pengukuran ini sama halnya dengan mengukur koefisien absorbsi yaitu dengan menggunakan metode tabung impedansi. Adapun rangkaian alat dapat dilihat pada Gambar 3.

Tabung yang digunakan telah diberi perlakuan khusus yaitu berupa ruang yang kedap suara, sehingga diharapkan data yang diambil(ruang penerima) merupakan bunyi yang diloloskan dari bahan (sampel uji). Metode yang digunakan selisih SPL yang diterima mikrofon pada ruang penerima dengan dan tanpa bahan.

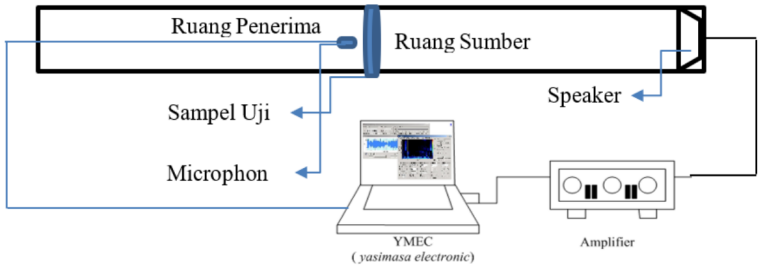

Gambar 3: Rangkaian alat untuk menentukan nilai noise reduction $(\mathrm{NR})$.

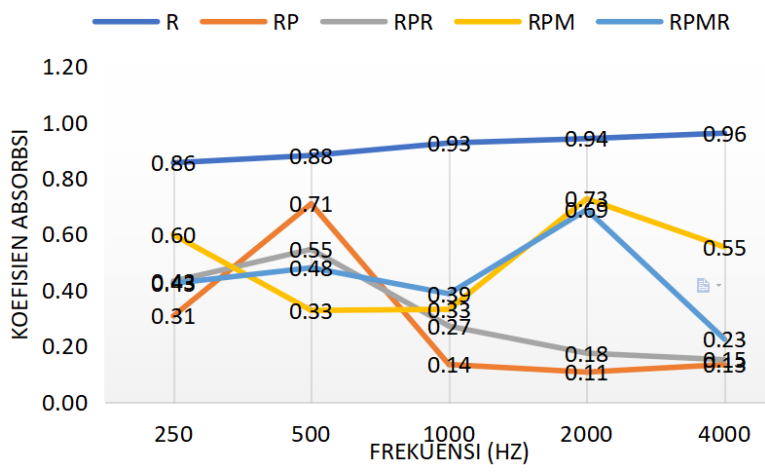

Gambar 4: Nilai $\alpha$ terhadap fungsi frekuensi.

\section{HASIL DAN DISKUSI}

Pada pelaksanaan penelitian ini telah dilakukan beberapa pegambilan data, adapun data yang diambil yaitu koefisien absorpsi bunyi dan NR. Data yang diambil disini bertujuan untuk menentukan besarnya koefisien absorpsi bunyi dan pola hamburan oleh panel akustik.

\section{Koefisien absorbsi bunyi}

Pengukuran ini menggunakan metode tabung impedansi, prinsip dasar metode tabung impedansi adalah refleksi,absorpsi dan transmisi gelombang bunyi oleh permukaan bahan pada suatu ruang tertutup, dimana bahan tersebut digunakan untuk melapisi permukaan dinding ruang tertutup. Adapun hasil pengukuran yang diperoleh dapat dilihat pada Gambar 4.

Data nilai $\alpha$ yang ditunjukkan Gambar 4, rockwool (R) memiliki nilai $\alpha$ yang paling tinggi pada semua frekuensi. Hal ini sesuai dengan karakter dari nilai $\alpha$ dari sebenarnya yaitu berkisar 0,9. Pengujian $\mathrm{R}$ digunakan sebagai bahan pembanding terhadap alat uji tabung yang digunakan. Bahan RP merupakan bahan obsorber pada frekuensi $500 \mathrm{~Hz}$, hal ini berarti bahwa resonator RP dapat digunakan untuk mengansorbi bunyi pada frekuensi $500 \mathrm{~Hz}$ (misalnya bunyi AC dan hujan). Hal ini juga sama halnya pada resonator RPR juga mampu mengabsorbsi pada $500 \mathrm{~Hz}$, namun nilainya lebih kecil jika dibandingkan tanpa rockwool. Sehingga dapat dilihat bahwa penambahan rockwool pada resonator tidak begitu signifikan.

Sedangkan untuk resonator jenis RPM dan RPMR memiliki nilai $\alpha$ yang tinggi pada frekuensi $500 \mathrm{~Hz}$ dan $2000 \mathrm{~Hz}$. Nilai ini menunjukkan bahwa dengan penambahan mozaik mampu meyerap bunyi pada frekuensi $2000 \mathrm{~Hz}$. Sehingga 


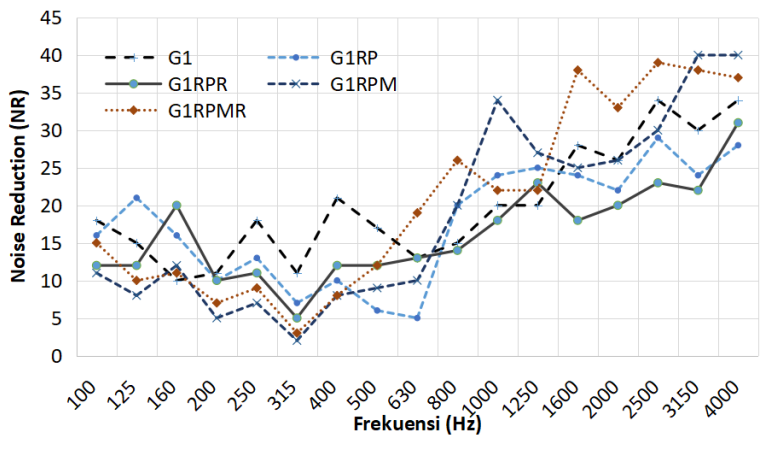

Gambar 5: Grafik nilai NR terhadap frekuensi.

bahan tersebut mampu mengurangi bunyi pada ruangan oleh sumber yang memiliki frekuensi $500 \mathrm{~Hz}$ dan $>2000 \mathrm{~Hz}$. Nilai yang ditunjukkan adalah 0,69 dan 0,73 hal ini berarti mampu menyerap bunyi hampir 70\%. Frekuensi tersebut identik dengan frekuensi percakapan. Dengan kemampuan menyerap bunyi yang tinggi pada frekuensi $2000 \mathrm{~Hz}$, penambahan batok dapat mengatasi permasalahan apabila ruangan tersebut terjadi gema/echo.

\section{Nilai Noise Reduction (NR)}

Pada sub bab sebelumnya dibahas bahwa dalam penelitian ini juga dilakukan pengukuran nilai NR yang berhubungan dengan kemampuan mentransmisikan bunyi. Untuk mempermudah menganalisa peneliti menggunakan bahan tambahan lain yang digunakan yaitu gipsum. Sampel gipsum merupakan bahan material yang sering dipakai dalam membuat partisi. Selain itu gipsum juga memiliki nilai NR yang cukup tinggi sehingga dalam penelitian ini melibatkan beberapa variasi dalam pengukuran. Data tersebut dipoleh ketika dengan dan tanpa bahan seperti ditunjukkan pada Gambar 4. Kemampuan dalam mentransmisikan bunyi diperoleh dengaan mengurangkan SPL tanpa bahan dan ketika ada bahan dengan syarat tabung impedansi yang digunakan adalah kedap suara. Bunyi yang diterima oleh mikrofon benar-benar merupakan bunyi yang tembus dari bahan. Data hasil perhitungan kemampuan dalam mentransmisikan bunyi dapat dilihat pada Gambar 5.

Dari nilai yang diketahui Bahwa dengan penambahan batok kelapa pada resonator mampu menaikkan nilai NR sekitar 10 dB. Nilai NR total yang dicapai G1RPM dan G1RPMR menunjukkan nilai yang cukup besar mulai frekuensi $500 \mathrm{~Hz}$ sudah mampu $30 \mathrm{~dB}$. Penunjukan angka NR 30-40 dB, nilai ini berarti suara keras terdengar tetapi harus lebih didengarkan. Namun pada bahan G1RPMR untuk frekuensi tinggi $4000 \mathrm{~Hz}$ mencapai nilai $50 \mathrm{~dB}$ yaitu nilai insulasi yang lebih tinggi apabila ada bunyi $80 \mathrm{~dB}$ yang masuk dalam ruang hanya $30 \mathrm{~dB}$ yang tidak akan mengganggu bunyi asli di dalam ruang.

\section{SIMPULAN}

Adapun simpulan yang dapat diperoleh dalam penelitian ini adalah bahwa resonator dengan penambahan batok kelapa mampu mereduksi bunyi khususnya pada frekuensi 2000 $\mathrm{Hz}$ sebesar 0,7, dan kemampuan penambahan batok pada resonator menambahkan nilai NR sebesar $10 \mathrm{~dB}$. Total kemampuan dalam mentransmisikan bunyi 30-40 dB.
[1] L. Beranek, "Concert Hall and Opera House; Musics, Acoustics and Architecture", Edisi ke-2, Springer, 2004.

[2] P. DAntonio, T. Cox, "Acoustic absorber and diffusers: theory, design and application", Edisi 2 Spoon Press London, 2004.

[3] Nur Salam, "How to make panel Acoustic Diffuser wall", Pemanfaatan limbah tempurung kelapa menjadi panel acoustic diffuser wall, 2015. https://www.youtube .com/ watch? $\mathrm{v}=\mathrm{U} 9 \mathrm{Fg} 4 \mathrm{PE} 712 \mathrm{w}$.
[4] S. Indrawati, "Innovative Coco Shell Resonator (CSR) Panels for Acoustic Performance", In Proceedings of the Engineering of physics, Procedia Engineering, vol. 170, pp. 293- , 2017.

[5] D.A. Russel, "Absorption Coefficient and Impedance", Science and Matheatics Departement, Kettering University, Flint, MI, 48504 . 